\title{
Beliefs and practices of Iranian pregnant mothers regarding vitamins and minerals
}

\author{
S.O. Mashayekhi, ${ }^{1}$ M. Dilmaghanizadeh, ${ }^{2}$ Z. Fardiazar, ${ }^{3}$ R. Bamdad-Moghadam ${ }^{4}$ and M. Ghandforoush-Sattari ${ }^{5}$
}

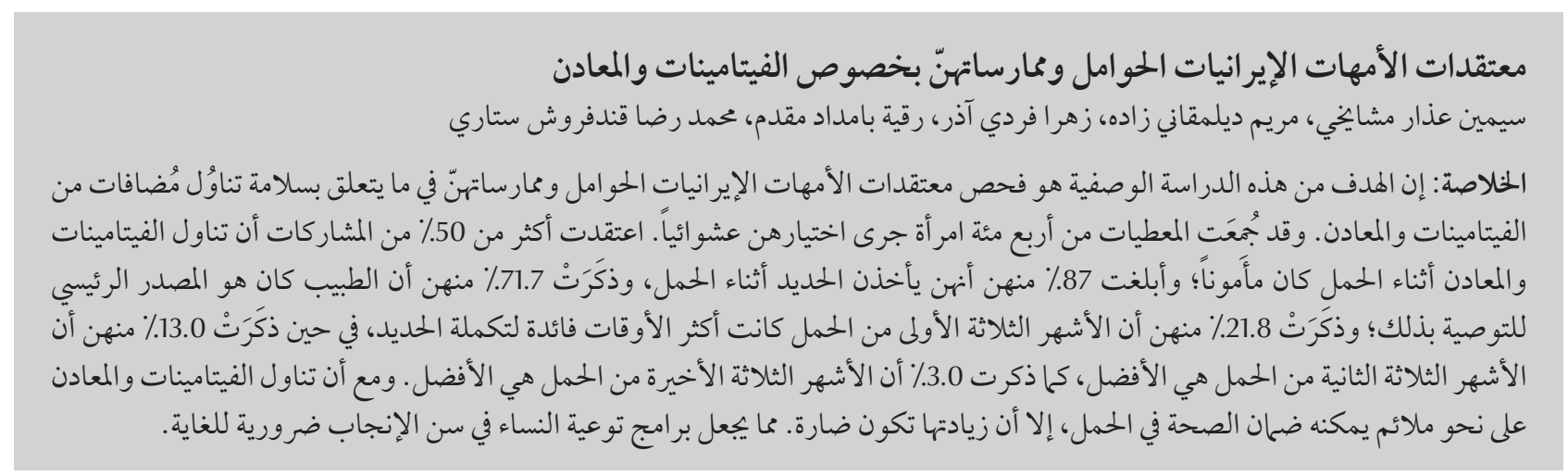

ABSTRACT The objective of this descriptive study was to examine the vitamin and mineral supplements safety beliefs and practices of Iranian pregnant women. Data were collected from 400 randomly chosen women. More than $50 \%$ of the participants believed that taking vitamins and minerals during pregnancy was safe; $87 \%$ reported taking iron during pregnancy, of which $71.7 \%$ reported their doctor as the main recommender; $21.8 \%$ reported first trimester as the most beneficial time for iron supplementation, $13.0 \%$ second trimester and $3.0 \%$ third trimester. Although an appropriate intake of vitamins and minerals can assure health in pregnancy, excess can be harmful. Educational programmes for women of childbearing age are necessary.

\section{Croyances et pratiques des femmes enceintes iraniennes au sujet des vitamines et des minéraux}

RÉSUMÉ L'objectif de la présente étude descriptive était d'examiner les croyances en termes de sécurité et les pratiques des femmes enceintes iraniennes concernant les compléments en vitamines et en minéraux. Des données ont été recueillies auprès de 400 femmes choisies au hasard. Plus de $50 \%$ des participantes pensaient que la prise de vitamines et de minéraux pendant la grossesse était sans danger; $87 \%$ d'entre elles affirmaient prendre du fer pendant leur grossesse, sur recommendation de leur médecin principalement pour $71,7 \%$ de ces femmes ; $21,8 \%$ étaient persuadées que le premier trimestre de grossesse était le moment le plus bénéfique pour la prise de complément en fer, 13,0 \% se prononçaient pour le deuxième trimestre et 3,0 \% penchaient pour le troisième trimestre de grossesse. Si la prise de compléments en vitamines et en minéraux permet de rester en bonne santé pendant la grossesse, une dose excessive peut être nocive. Des programmes d'éducation destinés aux femmes en âge de procréer s'avèrent nécessaires

\footnotetext{
${ }^{7}$ National Public Health Management Centre, ${ }^{2}$ Department of Clinical Pharmacy; ${ }^{5}$ Haematology and Oncology Research Centre, Department of Pharmacology and Toxicology, Faculty of Pharmacy; ${ }^{3}$ Faculty of Medicine; Tabriz University of Medical Sciences, Islamic Republic of Iran (CorrespondencetoS.O.Mashayekhi:mashayekhis@yahoo.co.uk).

${ }^{4}$ Petroleum Industrial Healthcare Organization (North-west branch), Nore-Nejat Hospital, Tabriz, Islamic Republic of Iran.

Received: 24/05/09; accepted: 27/08/09
} 


\section{Introduction}

Pregnancy is one of the most nutritionally demanding periods of a woman life; the extra nutrition is needed for growth of the fetus [1]. The woman's body acts as the source of nutrients for growth of the fetus [2,3] and gets these either through food or supplements. During pregnancy, the need for vitamins and minerals is clear. These have significant effects on fetal growth and development, and also on the mother's health. Examples include folic acid for prevention of neural tube defects in the fetus [4]; folic acid, vitamin $B_{12}$ and iron for prevention and treatment of anaemia in the mother [5]; iodine for preventing goitre in the mother and child $[6,7]$; calcium [8] magnesium for synthesis of new tissue, both fetal and maternal [9]; vitamin E for protective effects against preeclampsia and hypertension [10]; and magnesium to reduce the incidence of premature birth [11].

Iron deficiency is the most common nutritional deficiency worldwide and is the most common cause of anaemia in pregnancy [12] and high prevalence of iron deficiency anaemia during pregnancy has been documented in the Islamic Republic of Iran (25.8\%-35.6\%) [13-15].

Preconception and during pregnancy there is an increased requirement for vitamins and minerals, which may not be adequately provided by food intake and may require additional supplementation [3]. It is important to remember that not only is good nutrition, including vitamins and minerals, beneficial for the growth of the foetus inside the womb, it is beneficial years later in life $[16,17]$ for the prevention of chronic diseases in adulthood [18].

Previous studies have shown a high level of consumption of vitamin and mineral supplements during pregnancy [19-23]. But it must be remembered, particularlyduring pregnancy, that more does not always mean better. Although
Willett and Stamfer showed greater benefit than harm in recommending a daily multivitamin supplement that does not exceed the daily recommendation for most adults and noted that a multivitamin is especially important for women who might become pregnant [12], it should be remembered that high doses of single vitamins can be dangerous during pregnancy and selfadministration of multiple supplements is an easy way to overdose. Examples of these are vitamins A, K [24] and D and minerals such as chromium, copper, zinc, calcium and magnesium [25].

The knowledge of a pregnant woman of safety, necessity, and adequate period of the vitamins and minerals supplementation might not be as important as the consumption itself but is still considered crucial for correct usage. There have been many studies examining the level of knowledge of pregnant women on the safety and necessity of using folic acid or other drugs in pregnancy: our previous study is an example [26]. But examining the level of knowledge on other vitamins and minerals has not been done properly.

Our hypothesis was that the level of believe in safety of vitamins and minerals in pregnancy would be high regardless of their real safety profile. The aim of the present study was to assess the level of knowledge among pregnant women regarding the safety of vitamins and minerals supplementation.

\section{Methods}

We randomly selected our participants using simple random sampling using an Excel spreadsheet (RANDBETWEEN formula). Out of a total of 427 selected, 400 women in postnatal wards and attending for their last prenatal visit consented to participate in this study. The setting was 2 maternity hospitals and 2 private clinics in Tabriz, northwestern Islamic Republic of Iran, during the period of 2006-2007. We tried to cover women from every area in Tabriz. The first hospital was a private one with about 4000 deliveries per year serving a mixed population of pregnant women from urban, semi-rural and rural areas; the second hospital was a governmentrun one with about 5500 deliveries per year serving a much wider population. The 2 hospitals were located in 2 different sites of Tabriz with different population patterns. The clinics included 1 private and 1 public, and these were also located in different sites from each other and from the hospitals.

The inclusion criteria were women in their last month of pregnancy or those who had delivered their baby and just moved to postnatal ward. We excluded women with difficult or complicated deliveries from participation.

Because the study was not interventional, according to the university regulations, approval was not required but we obtained permission for the study from the directors of midwifery services and chairmen of the divisions of obstetrics and gynaecology of each unit. Prior to the study all participants were given an information sheet including the purpose of study and the method of the study. The women were given adequate time to make an informed decision or consult with their physician or relatives Written consent was obtained from each subject prior to the study, signed by subjects and a witness. Written informed consent was obtained from each subject prior to the study.

A structured questionnaire was used in a face-to-face encounter between the subjects and a pharmacy student in a descriptive study. We distributed 200 questionnaires in the public facilities and 200 in the private facilities. Questions covered demographic characteristics and knowledge of subjects on vitamins and mineral supplements safety and necessity in pregnancy. Several questions regarding iron usage and safety were asked in another section. 


\section{Statistical analysis}

SPSS software, version 13.5 , was used for analysing data. The chi-squared test was used to assess the significance data distribution between variables in one question. Descriptive statistics, Student $t$-test, Pearson correlations and ANOVA were performed in this study. The results were reported as percent and statistical significance was considered at $P<0.05$.

\section{Results}

The data collected from 400 forms were analysed. Demographic data are presented in Table 1. The participants had a normal age distribution, with the mean age 26.4 (standard deviation $4.90)$ years; $45.8 \%$ were in their first pregnancy, and $7.5 \%$ reported unsuccessful previous pregnancies.

More than half of the participants believed in the safety of various vitamins (Table 2).

The majority of the participants also believed in the safety of minerals during pregnancy (Table 2). The formulation of multivitamins or multivitamins and mineral was considered safe by $78.8 \%$ of the women. Between $5 \%$ and $10 \%$ of the participants believed that the vitamins or minerals mentioned could be harmful for the fetus, but no-one believed that they could be harmful for the mother. The remainder did not know if these supplements could be harmful or not (30\%-35\% for various vitamins or minerals).

Only $52(13 \%)$ participants reported not using iron supplements during the pregnancy (Table 2). Of those who took iron supplementation, $248(71.7 \%)$ reported their doctor as their main recommender; 318 (79.5\%) believed iron supplementation was necessary in pregnancy; $21.8 \%$ considered the first trimester as the most beneficial time for iron supplementation, $13.0 \%$

\begin{tabular}{lrc}
\hline $\begin{array}{l}\text { Table 1 Demographic information for } \\
\text { Tabriz, 2006-2007 }\end{array}$ & pregnant or newly delivered women in \\
\hline Variable & No. & \\
Age group (years) & 20 & 5.0 \\
$15-21$ & 127 & 31.8 \\
$20-24$ & 160 & 40.0 \\
$25-29$ & 61 & 15.3 \\
$30-34$ & 30 & 7.5 \\
$35-39$ & 2 & 0.5 \\
$40-44$ & & \\
Gravidity & 183 & 45.8 \\
1 & 118 & 29.5 \\
2 & 99 & 24.7 \\
$3+$ & & \\
Education & 184 & 46.0 \\
High school or lower & 147 & 36.8 \\
High school diploma & 69 & 17.3 \\
University & & 72.3 \\
Residence & 289 & 27.8 \\
Urban & 111 & \\
Rural & & \\
\hline
\end{tabular}

the second trimester and 3.0\% the third trimester.

\section{Discussion}

In the present study, the majority of the participants believed in the safety of vitamins and minerals supplements (in any dose) for the fetus and mother during pregnancy. In addition, it was generally believed that more can be better and even safe for both mother and fetus. This is of concern because it is known that excess doses of some vitamins or minerals could be dangerous; for example, in the FDA Classification of drug safety during pregnancy, taking high doses of vitamin $\mathrm{A}$ is classified in category X (contraindicated in women who are or may become pregnant because of evidence of greater risk than any possible benefit); vitamin $\mathrm{K}$ is also classified in category X, particularly during the last 3 months of pregnancy [24]; taking high doses of Vitamin D is classified in category D (drugs with positive evidence of human fetal risk, but the benefits may be acceptable despite the risk), [25]. Furthermore, high doses of zinc in the third trimester have been reported to cause preterm deliveries and stillbirths, calcium carbonate during the first trimester could cause congenital anomalies, and use of high regular doses of magnesium are associated with neonatal hypermagnesemia, drowsiness, respiratory distress, decreased muscle tone or cardiovascular impairment [25]. Therefore, high doses of such vitamins or minerals may potentially harm the fetus and cause toxicity while a pregnant mother thinks she is taking potentially beneficial supplements. This demonstrates that our participants need further education about the safety of vitamins and minerals used in pregnancy.

The proportion who used iron supplements during pregnancy was high among our subjects, and it was highest among rural residents and those with a lower level of education. The reason for this could be that women in rural areas, who had lower education, are cared for mainly by the government- 


\begin{tabular}{lcc}
\hline Table 2 Beliefs and practices of 400 pregnant or newly delivered women in Tabriz, \\
2006-2007 regarding selected vitamins and minerals during pregnancy \\
\hline Item & No. & $\%$ \\
\hline Believe taking iron is necessary in pregnancy & 318 & 79.5 \\
Yes & 10 & 2.5 \\
No & 72 & 18.0 \\
Don't know & & \\
Beliefin safety of: & 234 & 58.5 \\
Vitamin A & 242 & 60.5 \\
B vitamins & 252 & 63.0 \\
Vitamin B & 235 & 58.8 \\
Vitamin C & 229 & 57.3 \\
Vitamin D & 234 & 58.5 \\
Vitamin E & 233 & 58.3 \\
Vitamin K & 324 & 81.0 \\
Folic acid & 276 & 69.0 \\
Calcium & 265 & 66.3 \\
Zinc & 340 & 85.0 \\
Iron & & \\
Practice & 348 & 87.0 \\
Took iron supplement in pregnancy & 248 & 71.7 \\
Doctor recommended & 97 & 24.3 \\
Health centre recommended & 16 & 4.0 \\
Others recommended or self-medicated & 0.0 \\
Pharmacy/drug store recommended & & \\
\hline & & \\
\hline
\end{tabular}

run health centres and receive iron supplements free of charge from these centres and as a result had increased consumption levels. Running similar schemes in the cities for all women could also increase iron consumption during pregnancy.

Vitamins and minerals are essential for the growth of the fetus, the pregnant woman's health and also for the future health of the baby and mother. An appropriate intake of vitamins and minerals provided by an adequate diet can assure higher levels of health for both the mother and her child, now and in future. The concept of value of vitamins and minerals in pregnancy could cause an increase in the intake of supplements containing them, as previous studies have shown [19-21]. This demonstrates the necessity for proper educational programmes for women of childbearing age regarding the safety of vitamins and minerals as well as other medicines.

Further detailed study on the pattern of vitamins and mineral consumption, especially iron usage during pregnancy, and effective factors on correct usage seems necessary.

\section{Acknowledgement}

The present study was part of the Pharm-D thesis of Dr Maryam Dilmaghanizadeh, "Awareness among pregnant women of the effects of drugs on the fetus and mother", thesis No 3373, Department of Clinical Pharmacy, Tabriz University of Medical Sciences.

\section{References}

1. Fowles ER. What's a pregnant woman to eat? A review of current USDA dietary guidelines and MyPyramid. Journal of Perinatal Education, 2006, 15:28-33.

2. Fahey PJ, Boltri JM, Monk JS. Key issues in nutrition. From conception through infancy. Postgraduate Medicine, 1987, 81(1):301-5;308.

3. Gardiner PM et al. The clinical content of preconception care: nutrition and dietary supplements. American Journal of Obstetrics \& Gynecology, 2008, 199(6 Suppl. 2):S345-S356.

4. Pitkin RM. Folate and neural tube defects. American Journal of Clinical Nutrition, 2007, 85(Suppl.):285S-288S.

5. Mahomed K. Iron and folate supplementation in pregnancy. Cochrane Database of Systematic Reviews, 2006(3):CD001135.

6. Azizi F. lodine nutrition in pregnancy and lactation in Iran Public Health \& Nutrition, 2007, 10(12A):1596-1599.

7. Patrick L. lodine: deficiency and therapeutic considerations. Alternative Medicine Review, 2008 13(2):116-127.
8. Rumiris D et al. Lower rate of preeclampsia after antioxidant supplementation in pregnant women with low antioxidant status. Hypertension in Pregnancy, 2006, 25(3):241-253.

9. Ajayi GO, Fadiran EO. Short time effect of Chemiron (a combination iron preparation), single iron, and different magnesium salts on plasma. Magnesium concentration during early pregnancy in Nigerian women. A preliminary report. Clinical \& Experimental Obstetrics \& Gynecology, 1998, 25(1-2):64-66.

10. Grischke EM. Ernahrung in der Schwangerschaft. Gesund essen-aber bitte nicht "fur zwei"! [Nutrition during pregnancy-current aspects]. MMW Fortschritte der Medizin, 2004, 146(11):29-30;32.

11. Taslimi MM et al. A national survey on preterm labor. American Journal of Obstetrics \& Gynaecology, 1989, 160(6):1352-1357.

12. Willett WC and Stampfer MJ. What vitamins should I be taking, doctor? New England Journal of Medicine, 2001, 345:18191824. 
13. Emamghorashi F, Heidari T. Iron status of babies born to irondeficient anaemic mothers in an Iranian hospital. Eastern Mediterranean Health Journal, 2004, 10(6):808-814.

14. Gholamreza V. Anemia in north of Iran (south-east of Caspian Sea). Pakistan Journal of Biological Sciences, 2007, 10(10):17031707.

15. Karimi M, Kadivar R, Yarmohammadi H. Assessment of the prevalence of iron deficiency anemia, by serum ferritin, in pregnant women of Southern Iran. Medical Science Monitor, 2002 8(7):CR488-492.

16. Wu G et al. Maternal nutrition and fetal development. Journal of Nutrition, 2004, 134:2169-2172.

17. Fall C. Cardiovascular disease: diet, nutrition and emerging risk factors. The report of a British nutrition foundation task force, in fetal and maternal nutrition. Oxford, Blackwell Science, 2005.

18. Godfrey KM, Barker DJ. Fetal nutrition and adult disease. American Journal of Clinical Nutrition, 2000, 71:1344-52.

19. Glover DD, Rybeck BF, Tracy TS. Medication use in a rural gynecologic population: prescription, over-the-counter, and herbal medicines. American Journal of Obstetrics \& Gynaecology, 2004, 190(2):351-357.

20. Lee $\mathrm{E}$ et al. National patterns of medication use during pregnancy. Pharmacoepidemiology \& Drug Safety, 2006, 15(8):537-545.
21. Menard MK. Vitamin and mineral supplement prior to and during pregnancy. Obstetric \& Gynecology Clinics of North America, 1997, 24(3):479-98.

22. Refuerzo JS et al. Use of over-the-counter medications and herbal remedies in pregnancy. American Journal of Perinatology, 2005, 22(6):321-324.

23. Skouteris $\mathrm{H}$ et al. Use of complementary and alternative medicines by a sample of Australian women during pregnancy. Australia New Zealand Journal of Obstetrics \& Gynaecology, 2008, 48(4):384-390.

24. Koren G. Special aspects of perinatal and pediatric pharmacology. In: Katzung BG. Basic \& clinical pharmacology, 9th ed. New York, McGraw-Hill, 2004:995-999.

25. Abai MR et al. Comparative performance of imagicides on Anopheles stephensi, main malaria vector in a malarious area, southern Iran. Journal of Vector Borne Diseases, 2008, 45(4):307-312.

26. Mashayekhi SO et al. Study of awareness among pregnant women of the effects of drugs on the fetus and mother in Iran. Health Policy, 2009, 91(1):89-93.

\section{WHO recommendations for induction of labour}

The primary goal of the above-mentioned guidelines is to improve the quality of care and outcomes for pregnant women undergoing induction of labour in under-resourced settings. The target audience of these guidelines includes obstetricians, midwives, general medical practitioners, health-care managers and public health policy-makers.

The guidance provided is evidence-based and covers selected topics related to induction of labour that were regarded as critical priority questions by an international, multidisciplinary group of health-care workers, consumers and other stakeholders.

Further information about this and other WHO publications is available at: http://www.who.int/publications/en/ 